
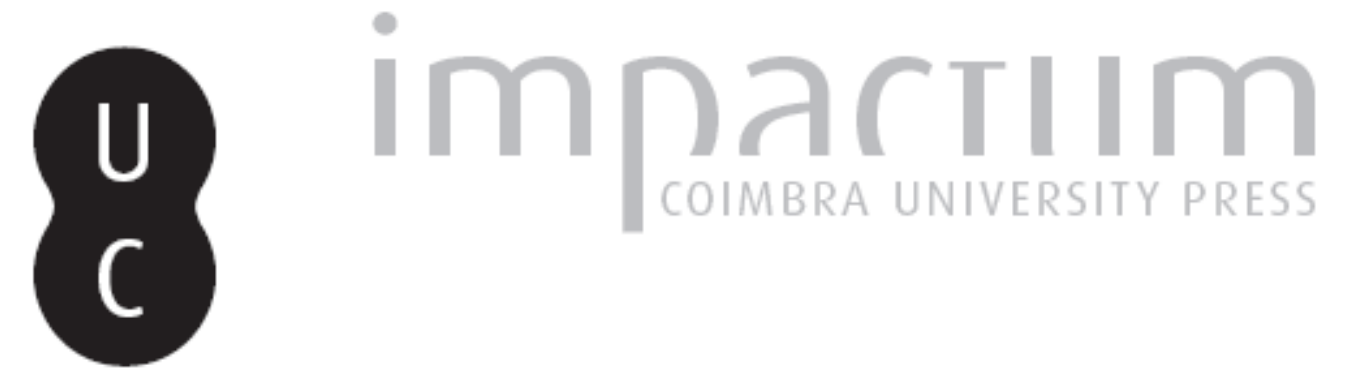

\title{
Textos da tragédia 1: o sonho de Atossa
}
Autor(es):
Azevedo, Maria Teresa Schiappa de
Publicado por:
Associação Portuguesa de Estudos Clássicos; Instituto de Estudos Clássicos
URL persistente:

DOI:

URI:http://hdl.handle.net/10316.2/30372

DOI:http://dx.doi.org/10.14195/0872-2110_53_2

Accessed : $\quad$ 26-Apr-2023 09:52:48

A navegação consulta e descarregamento dos títulos inseridos nas Bibliotecas Digitais UC Digitalis, UC Pombalina e UC Impactum, pressupõem a aceitação plena e sem reservas dos Termos e Condições de Uso destas Bibliotecas Digitais, disponíveis em https://digitalis.uc.pt/pt-pt/termos.

Conforme exposto nos referidos Termos e Condições de Uso, o descarregamento de títulos de acesso restrito requer uma licença válida de autorização devendo o utilizador aceder ao(s) documento(s) a partir de um endereço de IP da instituição detentora da supramencionada licença.

Ao utilizador é apenas permitido o descarregamento para uso pessoal, pelo que o emprego do(s) título(s) descarregado(s) para outro fim, designadamente comercial, carece de autorização do respetivo autor ou editor da obra.

Na medida em que todas as obras da UC Digitalis se encontram protegidas pelo Código do Direito de Autor e Direitos Conexos e demais legislação aplicável, toda a cópia, parcial ou total, deste documento, nos casos em que é legalmente admitida, deverá conter ou fazer-se acompanhar por este aviso.

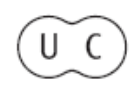




\section{Boletim de \\ Estudos Clássicos}

Associação Portuguesa de Estudos Clássicos Instituto de Estudos Clássicos

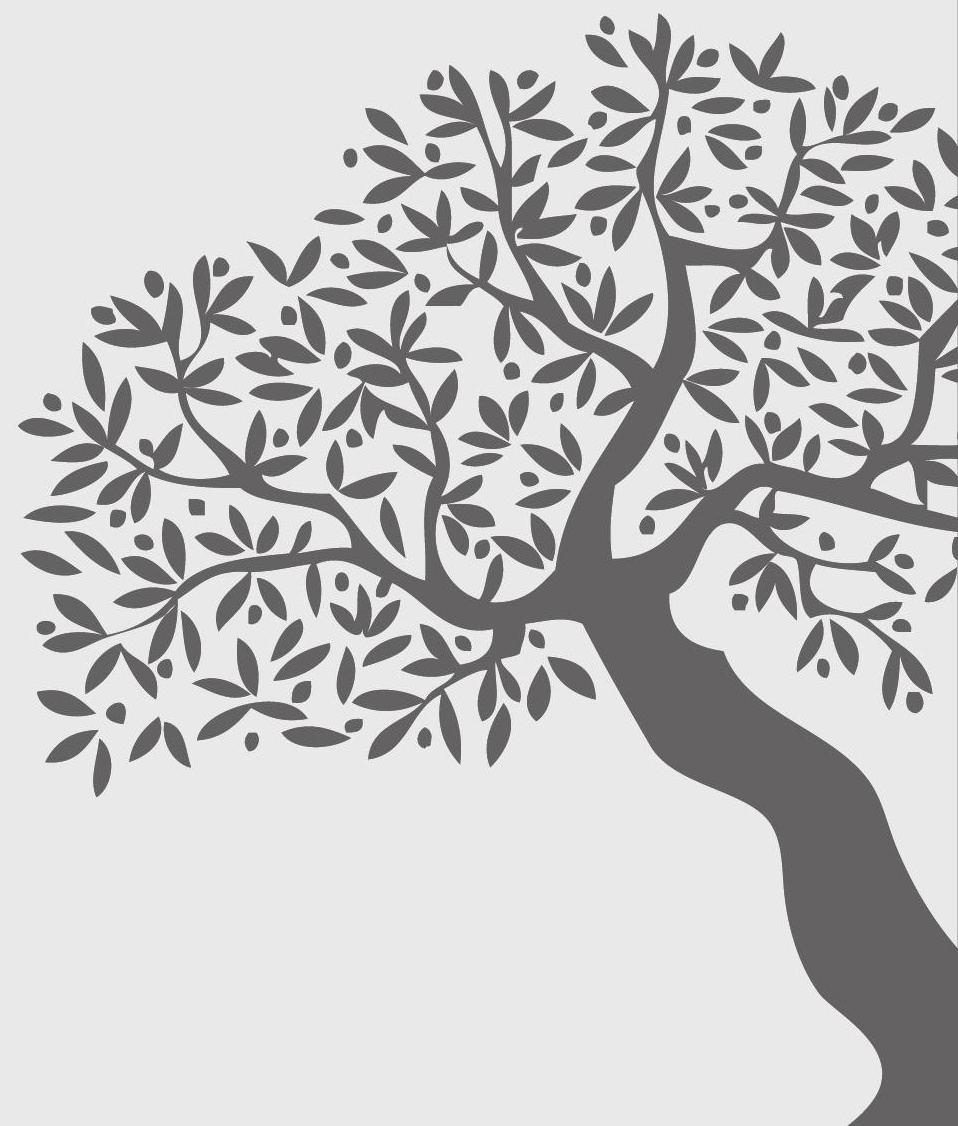

Coimbra

Junho de 2010 


\section{TeXTOS DA TRAGÉDIA 1. O SONHO DE ATOSSA}

Uma das assumidas barreiras, no ensino da literatura e da cultura grega, reside nas limitações do estudo do grego, que as recentes reformas do Ensino Secundário têm vindo a acentuar. Se não podemos, contudo, evitar o recurso à leitura dos principais textos em tradução - em particular, textos longos -, não é menos certo que o conhecimento e a análise de passos escolhidos no original enriquece significativamente a dinâmica de diálogo com o texto e a sensibilização para particularidades estilísticas e conceptuais, que uma tradução, por excelente que seja, só mitigadamente reproduz.

$\mathrm{O}$ contacto mais estreito que tive nos últimos tempos com a tragédia sugeriu-me a utilidade de reunir um conjunto de passos relativamente acessíveis mas relevantes, cujas dificuldades de tradução possam ser rapidamente eliminadas através de um comentário linguístico breve, canalizado para a interpretação textual. A preparação dos textos ficará assim bastante simplificada se os elementos forem previamente fornecidos ao aluno, permitindo rentabilizar os tempos de aula disponíveis e concentrá-los no seu principal objectivo: o estudo de questões literárias ou culturais específicas que levantam, e a forma como se integram no conjunto das obras a que pertencem. A nossa introdução procurará ainda sugerir associações várias, que o debate nas aulas poderá proporcionar.

O sonho da rainha Atossa, no $1^{\circ}$ episódio dos Persas (vv. 176-199), constitui, a meu ver, uma excelente possibilidade de opção, no estudo daquela que é a única tragédia de assunto histórico conservada. Nele está equacionada parte substancial da problemática em cena - o conflito entre a Grécia e a Pérsia, que as invasões persas vieram despoletar. A visão das duas jovens "irmãs", uma, que veste à maneira persa, outra, coberta com o peplo dórico, simbolizam idiossincrasias diferentes e até opostas, que a intervenção de Xerxes apenas vem acentuar: ao procurar apaziguá-las (é a interpretação da rainha), submetendo ambas ao mesmo jugo, a primeira aceita-o de bom grado; a segunda, pelo contrário, rejeita-o com violência, acabando mesmo por derrubar aquele que pretendia impor-lhe o freio. No sonho de Atossa 
antecipam-se assim motivos estruturais que vão sendo glosados ao longo da peça ${ }^{1}$, nomeadamente o contraste, insistido a todo o momento, entre a vivência da liberdade, que os Gregos afirmam e defendem, e o "direito do mais forte" (em termos parecidos com a posição de Cálicles, no Górgias platónico, esp. 482e-484c), que o despotismo oriental proclama, na pessoa de Xerxes. Contraste, até certo ponto, matizado pelo aparecimento de Dario (Xerxes rasga as vestes ao vê-lo), que prepara o inesquecível aparecimento do seu espectro, junto ao túmulo em que é invocado, para lamentar os desvarios do filho.

O motivo do sonho e a sua original configuração alegórica constituem assim um dos momentos artísticos marcantes na consciencialização que os Gregos elaboraram de si como povo: a alegoria das duas jovens irmãs, e da reacção radicalmente diversa ao jugo que lhes é imposto, imprime desde cedo uma imagem visual e poderosa, que a literatura e as artes plásticas aproveitaram. No Fedro platónico, por exemplo, o mito do cocheiro, que guia um carro levado por dois cavalos, de cores e temperamentos distintos, exprime, em termos por vezes reminiscentes da peça, o contraste entre a reacção do cavalo preto ("rebelde") à imposição do freio e a do cavalo branco, obediente e "sensato" (esp. 247b); nele se simboliza o conflito da alma, continuamente dividida entre os impulsos irracionais e terrenos, e a afinidade com as realidades inteligíveis e "celestes" a que a sua parte racional aspira. Por meados do séc. IV a.C., um famoso krater apúlio de volutas (o chamado Vaso de Dario) ecoa o motivo esquiliano, ao figurar duas jovens, Ásia e Hellas (Grécia), a primeira, conduzida por Apate (Engano) e a segunda, por Atena. Em baixo, está Dario sentado num trono e junto a ele uma figura masculina de pé, com a indicação Persai.

${ }^{1}$ Para a importância do motivo em Ésquilo vide M. F. Sousa e Silva, Ésquilo, o primeiro dramaturgo europeu (Coimbra 2005), pp.139-143. O sonho de Atossa é analisado em pormenor, nas suas ligações estruturais com a peça, por S. Marques Pereira, Sonhos e visões na tragédia grega (tese de doutoramento, Coimbra 2006, pp. 108-113). A. Moreau apresenta um minucioso comentário ao sonho, que nos foi de grande utilidade na elaboração das notas ("Le songe d'Atossa. Perses,176-214" in: A. Moreau et alii, Les Perses d'Eschyle, Montpellier 1993, pp. 29-45), bem como a edição comentada E. Hall (Aeschylus. Persae, Warminster 1997), que adoptámos na transcrição do passo. No tocante à tradução, a versão dos Persas de M. O. Pulquério (Lisboa 1998), que neste contexto será lida integralmente, apresenta um excelente compromisso entre nível literal e literário, pelo que nos dispensamos de apresentar outra versão. 
A visualização expressiva do sonho de Atossa e a reiteração, ao longo da obra, dos vários dados aí contidos poderão ter contribuído decisivamente (é a tese de E. Hall ${ }^{2}$ ) para a radicalização (ou "invenção") da antinomia grego/ bárbaro, nos termos em que a conhecemos na época clássica, embora acontecimentos anteriores possam ter tido um papel precursor, como a tomada de Mileto em 494 a.C. pelos Persas, sob o comando de Dario. No rescaldo desse evento, uma peça de Frínico, hoje perdida, evocava a violência inaudita do ataque e o martírio de uma população à mercê da crueldade do "bárbaro".

Estavam assim criadas as condições para que a primitiva oposição linguística ( (ßápßapos: o que não fala grego) adquirisse, no decorrer do séc. V a.C., uma conotação predominantemente étnica e civilizacional, que em Atenas a oratória política e a tragédia exploram amiúde em termos de

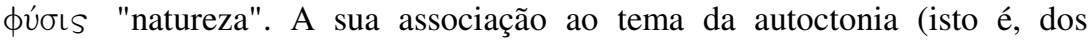
"nascidos da terra"), já provavelmente presente no Discurso Fúnebre de Péricles (Tucídides 2. 37), torna-se tópico quase obrigatório do elogio de Atenas e da sua supremacia, encarada em termos de "pureza racial" - como a sátira do Menéxeno platónico claramente mostra ${ }^{3}$. Ainda no século seguinte Aristóteles lembra, ao jeito de axioma, um conhecido verso de Eurípides: "É lógico que o Grego domine o Bárbaro", justificando que 'bárbaro' e 'escravo' têm a mesma natureza (Política 1252b, cf. Eurípides, Ifigénia em Áulide 1400).

Mas seria esse, de facto, o intuito de Ésquilo nos Persas? Independentemente da recepção que a peça encontrou nos seus contemporâneos e nas gerações seguintes, o tratamento dramático que ela oferece, tanto de Atossa como do círculo de Anciãos que a rodeia, não autoriza essa interpretação linear, que o sonho igualmente recusa. Ambas as

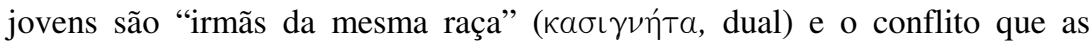

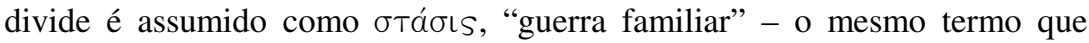

2 Em Inventing the Barbarian, Oxford,1988. No comentário à edição dos Persas atrás citada (esp. pp. 4-5), a A. privilegia o contexto emocional e cívico das primeiras décadas a seguir às invasões persas e frequentemente traduzido na repulsa pelo "bárbaro". Após a batalha de Plateias, foi aí instituído o festival de Eleutéria (Liberdade), celebrado todos os anos.

3 Vide M. T. Schiappa de Azevedo, Platão: helenismo e diferença (dissertação de doutoramento, Coimbra 2006/07), esp. pp. 149-160 e 191-196 e bibliografia aí citada. 
Platão restringe na República às dissensões entre Gregos, por oposição a тó $\lambda \in \mu o s$, a verdadeira guerra (isto é, entre Gregos e Bárbaros: cf. 470b471c). Não menos importante, neste contexto, é a dimensão mítica projectada na figura de Dario, e a expressiva apropriação do conceito helénico de üßpıs (termo que apenas ocorre neste momento da peça, vv. 801 e 821), para explicar o desfecho trágico do empreendimento de Xerxes ${ }^{4}$. A oposição grego/ bárbaro, bem sublinhada nos pormenores de "cor local" (vestuário, hábitos, etc.) e na linguagem de dominação, que a metáfora do "jugo" subentende, não impede uma real empatia com os Persas em cena (os que são também vítimas da guerra), remetendo para um característico "sentido da unidade humana" que é, conforme releva E. Hall ${ }^{5}$, timbre desta realização dramática.

É, pois, bem provável que, ao discutir a referida oposição à luz da

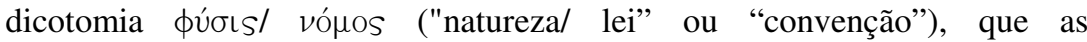
controvérsias sofísticas trazem a primeiro plano algumas décadas mais tarde, o orador e sofista Antifonte esteja muito mais próximo de Ésquilo do que

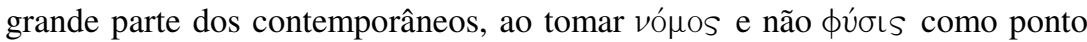
de partida para explicar as diferenças entre os povos ${ }^{6}$ :

[As leis de comunidades próximas, conhecemo-las e respeitamo-las], mas as de comunidades afastadas, não as conhecemos nem respeitamos. Portanto, tornamo-nos bárbaros uns relativamente aos outros, quando, por

${ }^{4}$ Não obstante ter sido Dario quem ordenou a $1^{a}$ invasão persa, repelida pelos Gregos em Maratona (490 a.C.), o prestígio que a sua figura impôs entre os Persas transmitiu-se aos Gregos e explica mesmo a secundarização do elemento histórico negativo em Ésquilo. Atitude semelhante é a de Platão nas Leis (695c-e), que elogia a aç̧ão legislativa de Dario e repartição de poderes em que estruturou o seu império, entendendo mesmo que, após o seu reinado, não houve mais nenhum rei persa que merecesse o epíteto de 'Grande' (Grande-Rei era a designação tradicional dos soberanos persas). Na Carta VII, Dario é comparado vantajosamente a Dionísio I, tirano de Siracusa (332a-b).

5 Aeschylus. Persians, p. 17.

6 O fragmento (44 D.-K. = P Oxy 3647) pertence a uma obra perdida e intitulada 'A $\mathrm{n} n$ $\theta \in \iota \alpha$ (Verdade). O início do fragmento é conjectural e há quem leia "deuses" em vez de "leis". Para a sua análise e contextualização, veja-se M. Gargarin, Antiphon. Oratory, Law and Justice in the Age of the Sophists (Austin 2002), esp. pp. 63-72. 
natureza, nascemos todos e em todos os aspectos igualmente capazes, tanto de ser Gregos, como de ser Bárbaros / .../ Pois nós todos respiramos o ar pela boca e pelas narinas, rimos quando os nossos espíritos estão felizes ou choramos quando estão atormentados, recebemos sons com os nossos ouvidos e vemos através da luz com os nossos olhos, e trabalhamos com as nossas mãos e passeamos com os nossos pés.

A peça de Ésquilo não esquece, de resto, a lenda que faz remontar Gregos e Persas a um mesmo herói mítico - Perseu, filho de Zeus e Dânae (cf. vv. 76-8, 270-271 e Heródoto 7.61 e 150). Embora indirectas, as referências são suficientemente evocativas de uma origem comum, que tanto o termo $\sigma \tau a ́ \sigma ı s$, aplicado ao conflito entre as jovens, como o qualificativo de

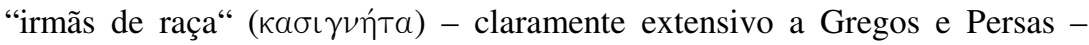
reforçam em termos de $\phi u ́ \sigma ı s^{7}$.

O sonho de Atossa (Aesch. Persae, vv. 176-199)

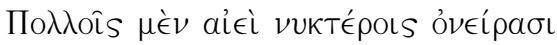

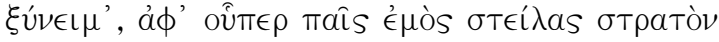

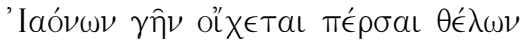

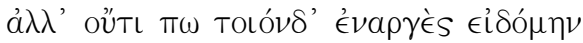

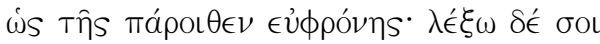

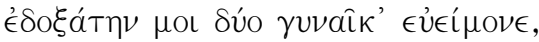

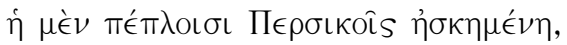

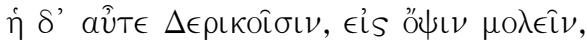

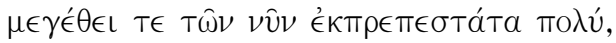

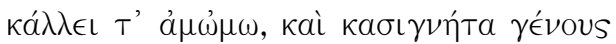

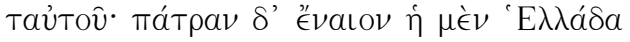

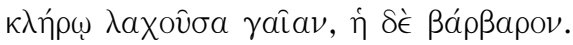

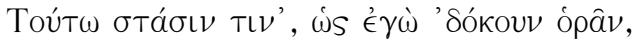

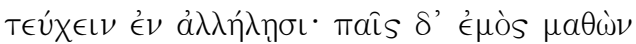

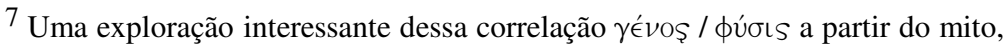
a que vem associar-se o tema da paideia, pode ver-se no Alcibíades I atribuído a Platão: os soberanos persas em nada são inferiores aos governantes atenienses, tendo, pelo contrário, a vantagem de serem desde crianças educados para as futuras funções, o que não sucede em Atenas (vide esp. 120e-121b, com o comentário de N. Denier, Plato. Alcibiades, Cambridge 2001, p. 171). 


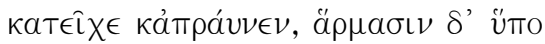

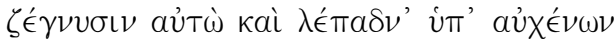

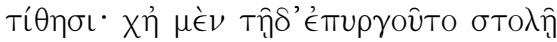

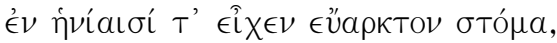

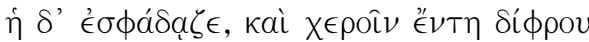

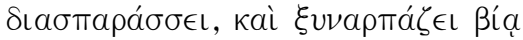

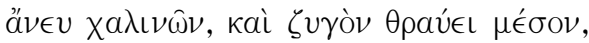

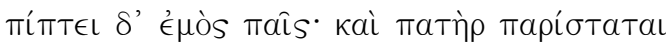

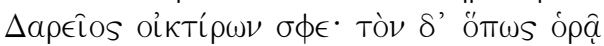

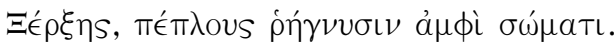

$\mathrm{Na}$ apreensão inicial do texto, é importante notar a correlação

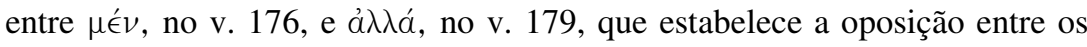
sonhos habituais da rainha e os dessa noite. Mév ả $\lambda \lambda \alpha^{\prime}$ equivale a $\mu \epsilon ́ v . . . \delta$ É..., lit. "por um lado ... por outro ...", com valor copulativo ou adversativo; de acordo com essas funções, deve traduzir-se por "e", "entretanto" ou "mas", na segunda frase coordenada. Usa-se á $\lambda \lambda \alpha$ é em vez de $\delta \epsilon ́$ (geralmente $\operatorname{sem} \mu \epsilon ́ v)$ quando uma das frases é negativa, embora não seja aqui o caso.

$\sigma u ́ v \in \iota \mu(\iota)+$ dat.: "estar com", "conviver". Lit. "conviver com sonhos" = "ter sonhos"; ő $\nu \in \iota \rho \rho \rho$, aTOS (geralmente pl.) "sonho", sinónimo de öv

ỏveıрo-ாódos "especialista (ou intérprete) de sonhos";

ỏ $\nu \in \iota \rho O-\mu a ́ v T \iota s$ "adivinho (através) de sonhos" cf. onírico, oniromancia.

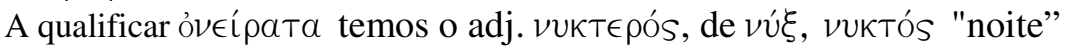

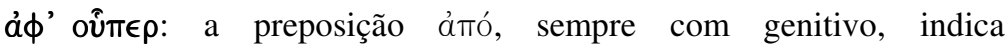
genericamente afastamento, no espaço ou no tempo. Com o pronome relativo tem frequentemente valor adverbial: $\alpha \dot{\phi}$ ' ố 'desde o momento (a altura) em que". (cf. $\epsilon i s$ ö "até ao momento em que"). A partícula - $\pi \in \rho$ ajunta a ideia de identidade ou reforço, podendo traduzir-se por "exactamente" (ö $\sigma \pi \epsilon \rho$ : "aquele mesmo que" ou "exactamente aquele que").

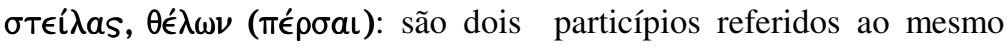

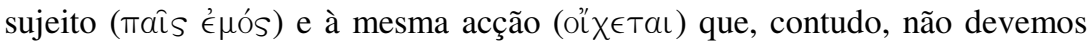

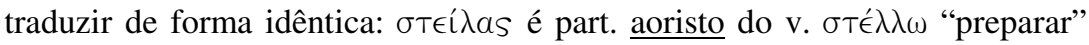
"equipar", e tem claramente valor temporal ("depois de formar um exército"); 
o segundo é part. presente do verbo $(\dot{\epsilon}) \theta \in \dot{\epsilon} \lambda \omega$ e exprime causa: "desejando destruir" = "com o desejo (intuito) de destruir".

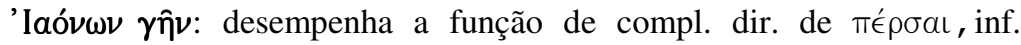
aoristo de $\pi \epsilon ́ \rho \theta \omega$, ‘destruir'. Os Persas designavam os Gregos por Iónios, não na forma grega ("I $\omega \nu \in S$ ) mas numa semelhante à apresentada no texto, com o óbvio intuito de dar "cor local" à fala da rainha.Yaunâ, como os Persas designavam os Gregos, comparece também na fala do mensageiro persa, nos Acarnenses de Aristófanes, v. 104.

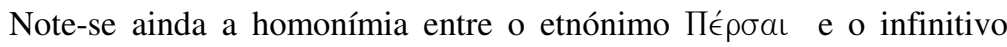

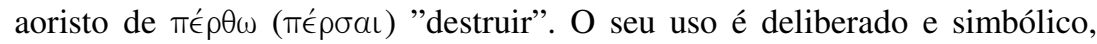
acentuando as conotações de devastação e ruína que a imagem dos Persas passou a representar para os Gregos, após as invasões.

ol’ $\chi \in$ Tal: de olXopal "ir-se embora", "partir"; usa-se poeticamente

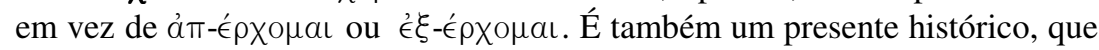
deve aqui ser traduzido como aoristo: "(daqui) partiu".

ov̉Tı: "de modo nenhum" ( $T$ "alguma coisa", tb. advérbio: "de algum modo").

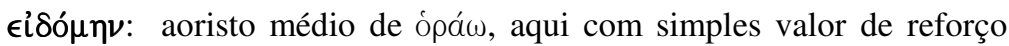
subjectivo da forma activa. O grego (como o latim) diz geralmente "ver um sonho" e não "ter um sonho".

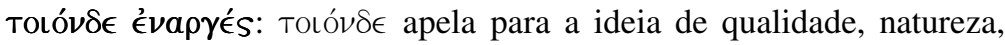
lit. "um (sonho) desta natureza claro" ou seja, "um sonho assim tão claro"; é

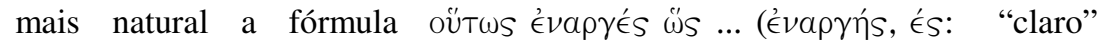
"nítido").

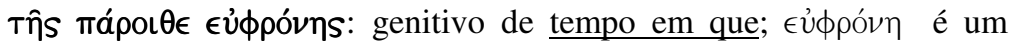
adjectivo substantivado (= $\epsilon \dot{u} \phi \rho o ́ \nu \eta ~ \nu u ́ \xi)$, com o valor de "benevolente", que se aplica à noite por eufemismo, isto é, com o propósito de afastar do espírito todas as coisas más que ela evoca (tal como as Erínias passam a ser designadas por Euménides, as "Benevolentes"). Note-se a posição atributiva do advérbio, isto é, imediatamente precedido de artigo. Nesta posição equivale a um adjectivo: "a noite de antes" = "a noite passada (anterior)". O 


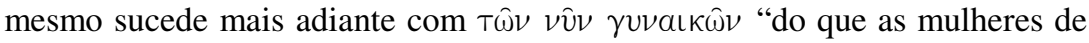
agora", i. e., "as mulheres comuns".

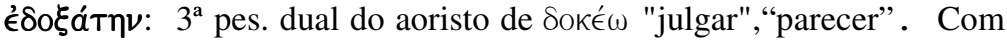

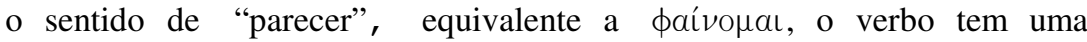
construção pessoal, idêntica à do lat. uideor. Ordem das palavras:

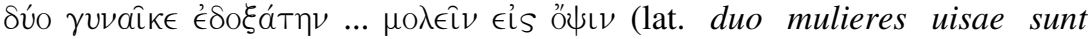

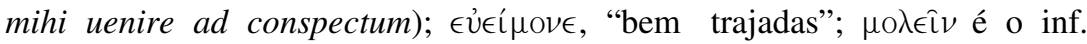
aoristo do v. $\beta \lambda \omega ́ \sigma \kappa \omega$ "ir/ vir" e öభıs, $\epsilon \omega$ s significa "vista", "visão" (cf.

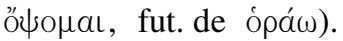

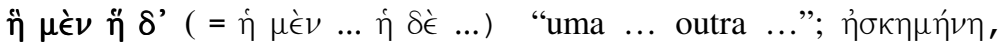

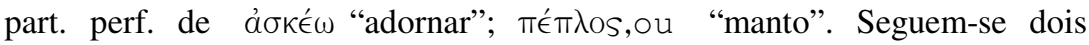
qualificativos no dual:

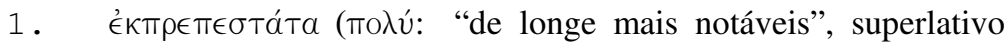

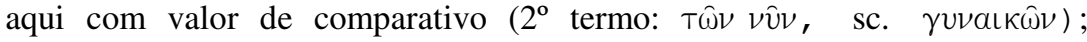

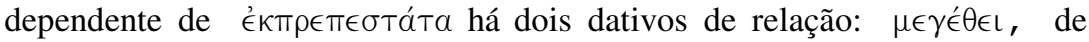

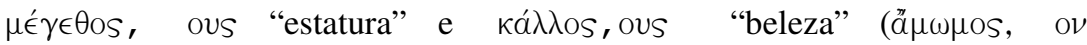
"irrepreensível”).

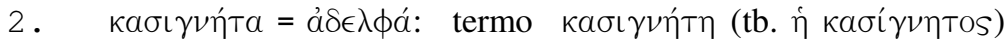
tem um valor enfático que a figura etimológica reforça: o elemento $-\gamma \nu \eta-$

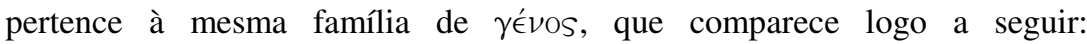

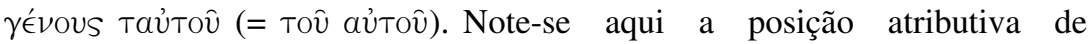
aủTós (precedido de artigo), lat. idem.

$\pi \epsilon ́ \pi \lambda$ ols $\Delta \omega \rho\llcorner\kappa o \hat{\sigma} \sigma \iota v$ : a linguagem poética usa indiferentemente, nos

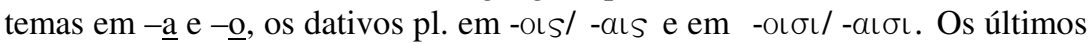
são característicos do iónico e do lésbico. Note-se $\alpha \hat{U}-T \epsilon$ (= $\alpha \hat{U})$, com o valor de reforço ou oposição. Aqui: "por sua vez".

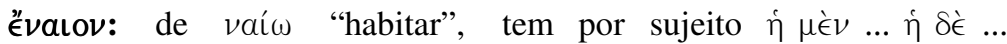

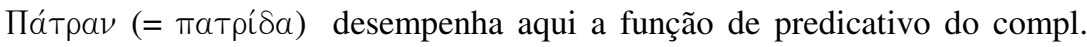
dir. (lit. "habitavam como pátria"); $\lambda \alpha \chi 0 \hat{v} \sigma \alpha$, part. aoristo de $\lambda a \gamma \chi \alpha ́ v \omega$

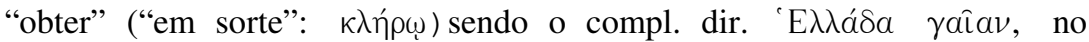

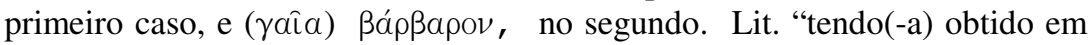
sorte" = "que obteve em sorte", "que a sorte lhe atribuiu". Note-se raîa $=\gamma \hat{\eta} \nu$. 


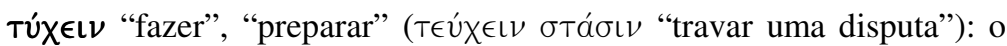
infinitivo em vez do imperfeito (" $\epsilon \in \cup X O \nu)$ deve-se ao cruzamento com a

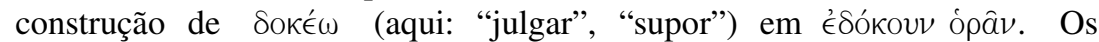

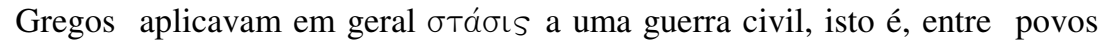
gregos (da mesma raça), o que está de acordo com a percepção das duas mulheres como "irmãs da mesma raça". Cf. Platão, República, 470b.

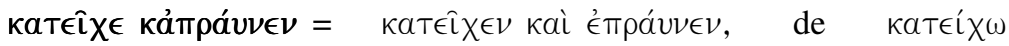
"conter" e $\pi \rho a v ́ v \omega$ "apaziguar".

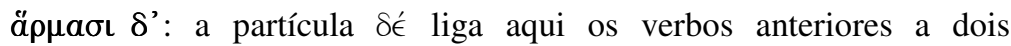

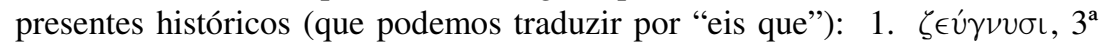

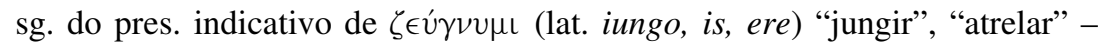

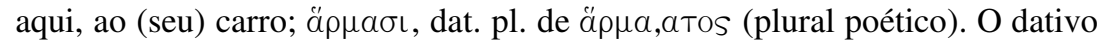
é regido pela prep. úmó, que vem depois do substantivo; nessa posição (em

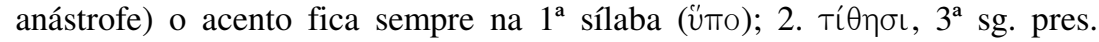

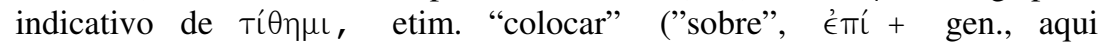

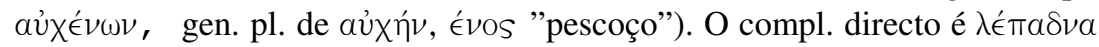

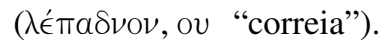

X’̉ $\mu \grave{\epsilon} \nu . . . \dot{\eta} \delta^{\prime}=\kappa a \grave{\eta} \dot{\eta} \mu \grave{\epsilon} \nu$, etc. Exprime o contraste de reacções.

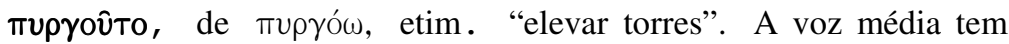
aqui um valor idêntico à nossa voz reflexa, podendo traduzir-se por

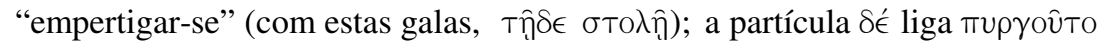

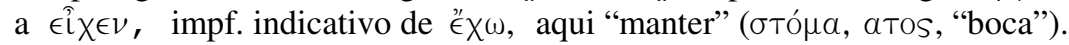

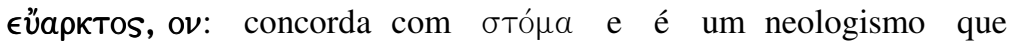
significa literalmente "fácil de governar" (cf. åp $\rho \omega)$; tem um valor proléptico: "de modo a deixar-se guiar"; ivía, as "rédea".

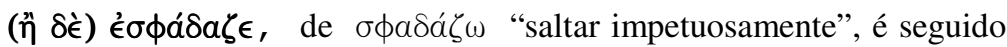
de outras formas verbais no presente (que é de manter na tradução):

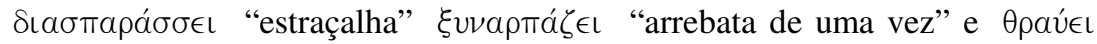
"quebra". A ideia de violência é reforçada pela forma adverbial ßía "à força".

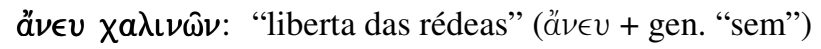




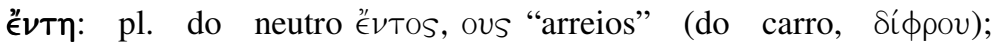

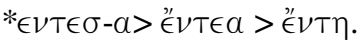

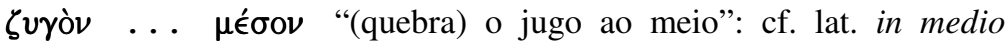
monte.

( $\pi i(\pi T \epsilon \iota) ~ \delta \underline{\epsilon}$, "então", "entretanto": a partícula não é aqui adversativa, marca apenas uma mudança de perspectiva, centrada agora por Atossa em

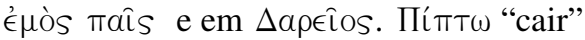

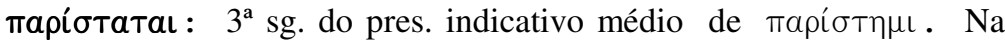
voz média, o verbo tem valor idêntico ao da nossa voz reflexa: "aproximarse", "postar-se junto de"; note-se tb. o uso iónico e poético de $\sigma \phi \epsilon$ não

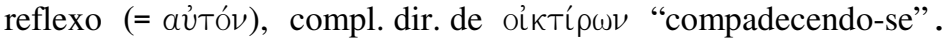

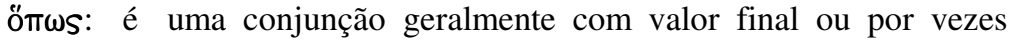
integrante; aqui é equivalente a ús com valor temporal (= ÖT

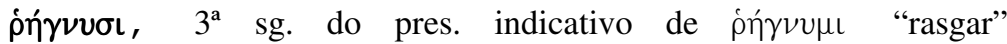

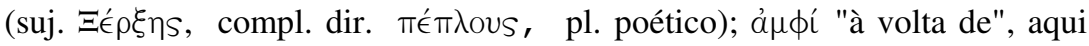
com dativo: $\sigma \omega \hat{\mu} \mu$, aTos "corpo".

MARIA TERESA SCHIAPPA DE AZEVEDO 